Journal of Zhejiang University-SCIENCE A (Applied Physics \& Engineering) ISSN 1673-565X (Print); ISSN 1862-1775 (Online)

www.jzus.zju.edu.cn; www.springerlink.com

E-mail: jzus@zju.edu.cn

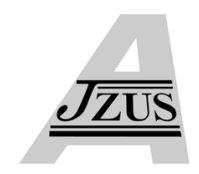

Editorial:

\title{
Air pollution control for a green future
}

\author{
Xiang GAO, Guest Editor-in-Chief \\ Cheng-hang ZHENG, Guest Editor \\ State Key Laboratory of Clean Energy Utilization, State Environ- \\ mental Protection Center for Coal-fired Air Pollution Control, \\ Zhejiang University, Hangzhou 310027, China \\ E-mail: xgao1@zju.edu.cn; zhengch2003@zju.edu.cn \\ https://doi.org/10.1631/jzus.A17EU001
}

Over the last decades, the production of energy from various sources (e.g. coal, crude oil, natural gas) has rapidly increased all over the world, partly caused by the relatively comfortable and prosperous life sought by people. It is true that energy utilization can bring tremendous benefit to humans. However, along with prosperity, environmental pollution cannot be neglected. To a great extent this pollution can be attributed to energy utilization, especially the combustion of fossil fuel. In general, pollution is the introduction of contaminants into the natural environment causing adverse changes. In the case of combustion, several toxic substance emissions such as sulfur dioxide $\left(\mathrm{SO}_{2}\right)$ and nitrogen oxides $\left(\mathrm{NO}_{x}\right)$ have been severely limited to very small values. To protect the environment from the adverse effects of emissions, many countries worldwide have adopted legislation to regulate various types of pollution as well as to alleviate their adverse effects. Both combustion modifications and after-treatment strategies have been employed to achieve the goal of emission control. During this process, various innovative methods have been invented and put into practice. For example, wet flue gas desulfurization (WFGD) can convert over $98 \%$ gaseous $\mathrm{SO}_{2}$ into solid $\mathrm{CaSO}_{4}$ while selective catalytic reduction (SCR) reduces gaseous $\mathrm{NO}_{x}$ by $\mathrm{NH}_{3}$ to form water and nitrogen (Zhong et al., 2008; Hu et al., 2017). Both methods have been extensively and rapidly commercialized worldwide, combined

\footnotetext{
D. ORCID: Xiang GAO, https://orcid.org/0000-0002-1732-2132; Cheng-hang ZHENG, https://orcid.org/0000-0003-0410- 2007

(C) Zhejiang University and Springer-Verlag GmbH Germany, part of Springer Nature 2018
}

with combustion modifications, effectively mitigating the harm to the atmosphere.

Although enormous success has been achieved concerning $\mathrm{SO}_{2}$ and $\mathrm{NO}_{x}$ reduction, other harmful substances remain to be dealt with. One such that attracts more and more attention in recent years is particulate matter (PM), because of its effects on both global climate and human health. For several decades, great efforts have been made to deal with PM emissions from energy utilization and a variety of new theories and control technologies have merged. To realize ultra-low PM emission, more attention is paid on ultra-fine particle removal. Some agglomeration technologies, e.g. acoustic agglomeration (Yan et al., 2016; Zhou et al., 2016), electrical agglomeration (Chang et al., 2015, 2017), and chemical agglomeration (Liu et al., 2016; Hu et al., 2018), are efficient pre-treatment methods to improve ultra-fine particle removal efficiency by enlarging particle size. Recently, condensable $\mathrm{PM}$ such as $\mathrm{SO}_{3}$ gains an increasing attention because it can lead to a variety of plant operation problems and plume opacity. Upgrading of wet electrostatic precipitator (Huang et al., 2016; Wu et al., 2017) becomes possible countermeasures to eliminate it to satisfactory emission requirement (Xu et al., 2016; Zheng et al., 2017).

As well as PM, we should also keep an eye on the heavy metals released during the process of energy utilization. Taking mercury as an example, it can be detected in flue gas. Because it is insoluble in water, highly volatile and chemically inert, it can exist in air, water, and soil over long distances and periods of time. Once it returns to the biosphere, mercury can bio-accumulate in the ecosystem and become a major threat to human health (Zhao et al., 2017). Strategies like adsorption/absorption, oxidation/reduction can be used to capture heavy metals and rehabilitate soil and water. However, creative materials, processes, and technologies are also needed.

Besides toxic materials, nontoxic carbon dioxide $\left(\mathrm{CO}_{2}\right)$ from fuel combustion becomes major concern recently and represents $76.7 \%$ of greenhouse gases 
(GHG). The initial concept for $\mathrm{CO}_{2}$ reduction is carbon capture and storage (CCS), which is the process of capturing wasted $\mathrm{CO}_{2}$ and depositing it into geological formations. Carbon capture and utilization (CCU) as an alternative method may offer the opportunity to significantly reduce GHG emissions. In this process, exhausted $\mathrm{CO}_{2}$ is converted into useful substances such as $\mathrm{CO}, \mathrm{CH}_{4}, \mathrm{CH}_{3} \mathrm{OH}$, and carbon. In addition to these techniques, we should emphasise related monitoring and measuring technologies, since these can provide insights into the mechanisms involved in the transportation and transformation of pollutants from the source to the environment.

In this special issue, we invited prestigious scientists in the field to share their expertise and perspectives. The collected papers cover the various topics aforementioned, such as PM removal, heavy metal removal, and $\mathrm{CO}_{2}$ utilization.

Zheng and Kanaoka (2018) reviewed recent developments in dust collection technology, especially bag filtration and electrostatic precipitators, as well as related ISO standards. The future prospects for these technologies were also outlined. It will be helpful to improve state-of-art particle removal technologies. Tao et al. (2018) applied a newly developed adhesive 3D multi-time scale discrete element method-computational fluid dynamic (DEMCFD) coupling approach to investigate the filtration of micron-sized particles by different types of fiber arrays, and the geometrical effects of different kinds of fiber arrays on the mesoscopic physics of the filtration process were examined. Their results showed that densified arrays may be suitable for a variety of purposes, e.g. baghouse filters or breathing masks regarding pressure drop and filtration efficiency. Chen et al. (2018) investigated the effect of relative humidity (RH) on non-refractory submicron aerosol evolution during summertime in Hangzhou, China. The evolution and size distribution of submicron aerosols, including organic and inorganic species, are explored by the high-resolution time-of-flight aerosol mass spectrometry (HR-ToF-AMS) method under a variety of $\mathrm{RH}$ levels. Their results showed that nitrate and chlorine mass concentrations and mass fractions continuously increased with increasing RH. However, many species show differences between low and high $\mathrm{RH}$ conditions (divided at $\mathrm{RH}=60 \%$ ).

Although facilities for $\mathrm{NO}_{x}, \mathrm{SO}_{x}$, and $\mathrm{PM}$ abatement have now been widely applied, efficient and effective control of trace metals, such as mercury, is still challenging (UNEP, 2013). Mu et al. (2018) adopted density functional theory (DFT) to investigate the adsorption mechanism of $\mathrm{Hg}$ on a $1 \mathrm{~T}-\mathrm{MoS}_{2}$ monolayer. Different possible adsorption positions on the $1 \mathrm{~T}-\mathrm{MoS}_{2}$ were examined. The results elucidated that chemisorption dominates the adsorption between $\mathrm{Hg}^{0}$ atoms and the $1 \mathrm{~T}-\mathrm{MoS}_{2}$. It was found that the $\mathrm{T}_{\mathrm{Mo}}$ (on top of the Mo atom) position is the strongest adsorption configuration among all the possible adsorption positions. Zheng et al. (2018) investigated the co-benefit of hazardous trace elements such as mercury $(\mathrm{Hg})$, arsenic (As), and selenium (Se) capture in dust removal devices of ultra-low emission coal-fired power plants. The results indicated that the low inlet temperature of low-low temperature electrostatic precipitator (LLT-ESP) had significant promotional effect on the simultaneous removal of $\mathrm{Hg}$, As, and Se. The smaller particle size of fly ash can be conducive to the adsorption of hazardous trace elements. The inhibitory effect of sulfur content in coal was significant for the enrichment of $\mathrm{Hg}$ and Se in fly ash.

As well as toxic substance removal, the recycling of exhaust gases shows promise. A typical case is the catalytic transformation of $\mathrm{CO}_{2}$ to value-added substances. Sagawa (2018) prepared catalysts with $\mathrm{Fe}, \mathrm{Ni}$, and $\mathrm{Cu}$ supported on $\mathrm{Al}_{2} \mathrm{O}_{3}$ and performed dry reforming of $\mathrm{CO}_{2}$, steam reforming of $\mathrm{CO}_{2}$, water gas shift reaction, and $\mathrm{CO}_{2}$ hydrogenation over these catalysts. It was found that by varying the ratios of $\mathrm{Fe}$, $\mathrm{Ni}$, and/or $\mathrm{Cu}$ over the composite materials, the yield and selectivity of the useful products such as $\mathrm{CO}$, $\mathrm{CH}_{4}$, and $\mathrm{C}$ are promising for further enhancement. Nowicka and Sankar (2018) reviewed important structural features relevant to Pd-based bimetallic systems and a few reactions relevant to environmental catalysis, i.e. $\mathrm{CO}$ oxidation, hydrocarbon oxidation, hydrodechlorination, and $\mathrm{NO}_{x}$ decomposition were illustrated. They believed that this review will inspire scientists to rationally design catalysts for a green and sustainable future. $\mathrm{Wu}$ et al. (2018) developed the rainbow refractometry method for in-situ characterization of gas-liquid precipitation reaction in $\mathrm{SO}_{2}$ and $\mathrm{CO}_{2}$ removal process. They tried to characterize the reaction process in-situ using the change of the refractive index of droplets during the gas-liquid absorption precipitation reaction process. Based on rainbow refractometry, the in-situ characterization of such a reaction was first studied, and its feasibility and effectiveness were verified through several experiments and detailed heat transfer analysis. 
We believe this special issue has provided a unique opportunity for researchers to present and discuss recent advances in air pollutant control and air quality management during energy utilization. The interaction of fundamental science and industrial application within topics was also particularly promoted by the high quality of the technical and scientific standard of the selected publications. We sincerely hope the most up-to-date view and outlook of the field that is shared in this special issue will move the research frontier forward, improve the understanding of air pollutant control technologies and strategies, as well as preserve existing know-how. We expect these cutting-edge articles will promote discussions among established scientists and could also provide benefit for the journal readers.

\section{References}

Chang QY, Zheng CH, Gao X, et al., 2015. Systematic approach to optimization of submicron particle agglomeration using ionic-wind-assisted pre-charger. Aerosol and Air Quality Research, 15(7):2709-2719.

Chang QY, Zheng CH, Yang ZD, et al., 2017. Electric agglomeration modes of coal-fired fly-ash particles with water droplet humidification. Fuel, 200:134-145. https://doi.org/10.1016/j.fuel.2017.03.033

Chen LH, Lv B, Zheng XJ, et al., 2018. Effect of relative humidity on non-refractory submicron aerosol evolution during summertime in Hangzhou, China. Journal of Zhejiang University-SCIENCE A (Applied Physics \& Engineering), 19(1):45-59. https://doi.org/10.1631/jzus.A1700567

Hu B, Yi Y, Zhou L, et al., 2018. Experimental and DFT studies of $\mathrm{PM}_{2.5}$ removal by chemical agglomeration. Fuel, 212:27-33.

$\mathrm{Hu} \mathrm{W}$, Zhang Y, Liu S, et al., 2017. Improvement in activity and alkali resistance of a novel $\mathrm{V}-\mathrm{Ce}\left(\mathrm{SO}_{4}\right)_{2} / \mathrm{Ti}$ catalyst for selective catalytic reduction of $\mathrm{NO}$ with $\mathrm{NH}_{3}$. Applied Catalysis B: Environmental, 206:449-460. https://doi.org/10.1016/j.apcatb.2017.01.036

Huang J, Wang H, Shi Y, et al., 2016. Performance of a pilotscale wet electrostatic precipitator for the control of sulfuric acid mist. Environmental Science and Pollution Research, 23(19):19219-19228. https://doi.org/10.1007/s11356-016-7151-x

Liu Y, Hu B, Zhou L, et al., 2016. Improving the removal of fine particles with an electrostatic precipitator by chemical agglomeration. Energy \& Fuels, 30(10):8441-8447. https://doi.org/10.1021/acs.energyfuels.6b00626

Mu XL, Gao X, Zhao HT, et al., 2018. Density functional theory study of the adsorption of elemental mercury on a $1 \mathrm{~T}-\mathrm{MoS}_{2}$ monolayer. Journal of Zhejiang UniversitySCIENCE A (Applied Physics \& Engineering), 19(1): 60-67. https://doi.org/10.1631/jzus.A1700079

Nowicka E, Sankar M, 2018. Designing Pd-based supported bimetallic catalysts for environmental applications. Journal of Zhejiang University-SCIENCE A (Applied
Physics \& Engineering), 19(1):5-20.

https://doi.org/10.1631/jzus.A1700257

Sagawa T, 2018. Conversion of $\mathrm{CO}_{2}$ to useful substances with composite iron, nickel, and copper catalysts. Journal of Zhejiang University-SCIENCE A (Applied Physics \& Engineering), 19(1):80-85. https://doi.org/10.1631/jzus.A1700056

Tao R, Yang MM, Li SQ, 2018. Filtration of micro-particles within multi-fiber arrays by adhesive DEM-CFD simulation. Journal of Zhejiang University-SCIENCE A (Applied Physics \& Engineering), 19(1):34-44. https://doi.org/10.1631/jzus.A1700156

UNEP (United Nations Environment Programme), 2013. Global Mercury Assessment 2013: Sources, Emissions, Releases, and Environmental Transport. https://www. unep.org [Accessed on Dec. 20, 2017].

Wu H, Pan DP, Bao JJ, et al., 2017. Improving the removal efficiency of sulfuric acid droplets from flue gas using heterogeneous vapor condensation in a limestone-gypsum desulfurization process. Journal of Chemical Technology and Biotechnology, 92(1):230-237. https://doi.org/10.1002/jctb.4974

Wu XC, Li C, Cao JZ, et al., 2018. In-situ characterization of gas-liquid precipitation reaction in a spray using rainbow refractometry. Journal of Zhejiang University-SCIENCE A (Applied Physics \& Engineering), 19(1):86-94. https://doi.org/10.1631/jzus.A1700240

$\mathrm{Xu} \mathrm{X}$, Zheng CH, Yan P, et al., 2016. Effect of electrode configuration on particle collection in a high-temperature electrostatic precipitator. Separation and Purification Technology, 166:157-163. https://doi.org/10.1016/j.seppur.2016.04.039

Yan JP, Chen LQ, Yang LJ, 2016. Combined effect of acoustic agglomeration and vapor condensation on fine particles removal. Chemical Engineering Journal, 290:319-327. https://doi.org/10.1016/j.cej.2016.01.075

Zhao H, Mu X, Yang G, et al., 2017. Graphene-like $\mathrm{MoS}_{2}$ containing adsorbents for $\mathrm{Hg}^{0}$ capture at coal-fired power plants. Applied Energy, 207:254-264. https://doi.org/10.1016/j.apenergy.2017.05.172

Zheng CH, Kanaoka C, 2018. Recent advances in dust collection technology and ISO standardization in bag filtration. Journal of Zhejiang University-SCIENCE A (Applied Physics \& Engineering), 19(1):21-33. https://doi.org/10.1631/jzus.A1700072

Zheng CH, Shen ZY, Chang QY, et al., 2017. Experimental study on electrostatic precipitation of low-resistivity high-carbon fly ash at high temperature. Energy \& Fuels, 31(6):6266-6273. https://doi.org/10.1021/acs.energyfuels. $7 \mathrm{~b} 00107$

Zheng CH, Wang L, Zhang YX, et al., 2018. Co-benefit of hazardous trace elements capture in dust removal devices of ultra-low emission coal-fired power plants. Journal of Zhejiang University-SCIENCE A (Applied Physics \& Engineering), 19(1):68-79. https://doi.org/10.1631/jzus.A1700229

Zhong Y, Gao X, Huo W, et al., 2008. A model for performance optimization of wet flue gas desulfurization systems of power plants. Fuel Processing Technology, 89(11):1025-1032. https://doi.org/10.1016/j.fuproc.2008.04.004

Zhou D, Luo ZY, Jiang JP, et al., 2016. Experimental study on 
improving the efficiency of dust removers by using acoustic agglomeration as pretreatment. Powder Technology, 289:52-59.

https://doi.org/10.1016/j.powtec.2015.11.009

\section{中文概要}

题 目: 大气污染治理助推绿色发展

概 要：化石燃料尤其是煤炭利用过程中排放的二氧化 硫、氮氧化物、颗粒物和重金属等污染物以及二 氧化碳等温室气体已引起国内外的广泛关注, 并 已成为能源环境领域的研究热点。近几年, 国内
外在烟气污染物控制以及 $\mathrm{CO}_{2}$ 捕集和利用方面取 得了显著的进展。然而如何进一步提高污染物的 脱除效率、如何实现多污染物高效协同脱除以及 如何实现污染物的资源化利用等方面尚需进一 步研究; 如何实现 $\mathrm{CO}_{2}$ 的资源化和循环利用也得 到国际上的普遍关注, 亟需基础研究支撑技术突 破。本专辑收集了在该研究领域具有影响力的研 究人员的最新研究成果和观点, 介绍了该领域的 最新研究进展, 希望能帮助读者了解相关研究工 作并促进研究人员开展讨论, 推进该领域的基础 研究和技术创新, 为实现能源消费清洁化、低碳 化和绿色化提供科学和技术支撑。

关键词: 化石燃料; 大气污染物; 二氧化碳; 绿色化

\section{Introducing Guest Editor-in-Chief and Guest Editors:}

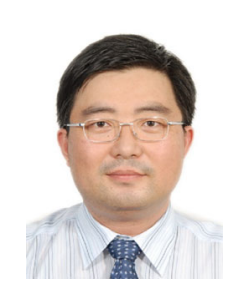

\section{Guest Editor-in-Chief}

Dr. Xiang GAO has been the Associate Editor-in-Chief of Journal of Zhejiang UniversitySCIENCE A (Applied Physics \& Engineering) since 2018.

Dr. Xiang GAO, Cheung Kong Professor, is winner of the National Science Fund for Distinguished Young Scholars and Senior Specialist of Zhejiang Province, China. Currently, Dr. GAO is the Dean of the College of Energy Engineering in Zhejiang University and the Director of the Coal-fired Air Pollution Control Engineering Center for the Ministry of National Environmental Protection. Dr. GAO's research focuses on simultaneous removal of multi-pollutants $\left(\mathrm{NO}_{x}, \mathrm{SO}_{x}\right.$, particulate matter and heavy metal, etc.) in flue gas under various coal compositions and working conditions. With the continuous support of the National Natural Science Foundation, the National Key Basic Research Program, and the National High Technology Research and Development Program of China, Dr. GAO has developed various technologies for flue gas purification including ultra-low emission (ULE) technology, wet flue gas desulfurization (WFGD)-based integrated high efficiency control technologies for $\mathrm{SO}_{x}, \mathrm{NO}_{x}$, and $\mathrm{Hg}$, and for multi-stage humidified semi-dry flue gas purification high-efficiency selective catalytic reduction (SCR), wet electrostatic precipitation (WESP), etc. Dr. GAO has won the National Award for Scientific and Technological Progress (second prize), National Award for Technological Invention (second prize), National Award for Teaching Achievements (second prize), Provincial Award for Technological Invention (first prize), Chinese Outstanding Patents Award, etc. Dr. GAO has published more than 120 SCI papers, more than 45 authorized invention patents (including 3 international patents) and more than 20 national/industrial standards.

\section{Guest Editors}

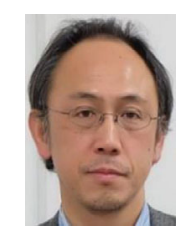

Dr. Takashi SAGAWA

Graduate School of Energy Science, Kyoto

University, Yoshida-Honmachi, Sakyo-Ku, Kyoto, Japan.

E-mail: sagawa.takashi.6n@kyoto-u.ac.jp

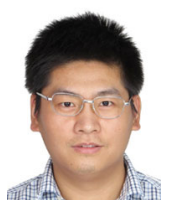

Dr. Cheng-hang ZHENG

State Key Laboratory of Clean Energy Utilization, Zhejiang University, Hangzhou, China. E-mail: zhengch2003@zju.edu.cn

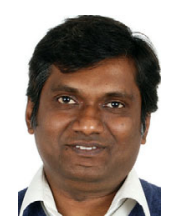

Dr. Meenakshisundaram SANKAR

Cardiff Catalysis Institute, School of Chemistry,

Cardiff University, UK.

E-mail: sankar@cardiff.ac.uk

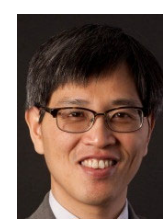

Dr. Changyu WU

Department of Environmental Engineering Sciences, University of Florida, Gainesville, FL, USA.

E-mail: cywu@ufl.edu

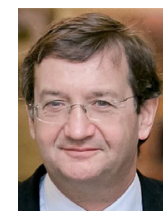

Dr. Enrico TRONCONI

Laboratorio di Catalisi e Processi Catalitici, Dipartimento di Energia, Campus Bovisa, Via La Masa 34, Politecnico di Milano, Italy. E-mail: enrico.tronconi@polimi.it 